\title{
As especificidades do debate público sobre as grandes infraestruturas. $O$ caso de Génova
}

The Specificities of the Public Debate on Large Infrastructures. The Case of Genoa

Les spécificités du débat public sur les grandes infrastructures. Le cas de Gênes

Luigi Bobbio

\section{OpenEdition}

\section{Journals}

Edição electrónica

URL: http://journals.openedition.org/rccs/4201

DOl: $10.4000 /$ rccs.4201

ISSN: 2182-7435

\section{Editora}

Centro de Estudos Sociais da Universidade de Coimbra

Edição impressa

Data de publição: 1 Dezembro 2010

Paginação: 189-203

ISSN: 0254-1106

\section{Refêrencia eletrónica}

Luigi Bobbio, «As especificidades do debate público sobre as grandes infraestruturas. O caso de Génova », Revista Crítica de Ciências Sociais [Online], 91 | 2010, colocado online no dia 16 outubro 2012 criado a 19 abril 2019. URL : http://journals.openedition.org/rccs/4201 ; DOI : 10.4000/rccs.4201 


\section{LUIGI BOBBIO}

\section{As especificidades do debate público sobre as grandes infraestruturas. O caso de Génova"}

O primeiro caso em Itália de debate público 'à francesa' sobre uma grande infraestrutura desenrolou-se em Génova, em 2009, sobre o projecto de desvio de uma auto-estrada que contorna a cidade. Este artigo analisa as características desse dispositivo com base na experiência genovesa: o conflito na origem do debate, a independência da comissão encarregada de o gerir, a organização do processo e a transparência da informação, a mobilização das comunidades locais e o confronto em torno do problema da sua representação, o desequilíbrio na participação dos cidadãos, as discussões sobre a oportunidade e as características do projecto, a natureza do debate (entre confronto e deliberação) e, por fim, o seu resultado. $O$ artigo termina com uma discussão sobre a "ambivalência" do debate público de modelo francês.

Palavras-chave: conflitos; debate público; democracia deliberativa; infraestruturas urbanas; participação política.

O debate público sobre grandes infraestruturas é uma fórmula participativa que foi introduzida em França em 1995 e que, desde aí, foi posta em prática em cerca de quarenta casos (Mansillon, 2006; Revele et al., 2007). Em Itália, um mecanismo semelhante foi proposto em 2007 no concelho de Montaione, ${ }^{1}$ a partir da discussão pública dos conteúdos da lei sobre a

\footnotetext{
* O artigo é inspirado num seminário decorrido no CES de Coimbra no dia 8 de Junho de 2010, intitulado "Deliberação fria vs. deliberação quente: o caso do debate público sobre a auto-estrada de Génova". Sobre o tema, o autor publicou também um outro artigo (diferente do presente) intitulado "Il dibattito pubblico sulle grandi opere. Il caso dell'autostrada di Génova" na Rivista Italiana di Politiche Pubbliche, 1, 2010.

${ }^{1}$ Este caso de debate público, inspirado no modelo francês, desenrolou-se no pequeno município toscano de Montaione entre Setembro e Dezembro de 2007, antes da entrada em vigor da lei regional sobre a participação. Tratou-se quase de uma experiência-piloto, cujo objecto foi a transformação do burgo medieval de Castelfalfi num empreendimento turístico promovido por uma multinacional alemã (http://www.dp-castelfalfi.it/home.page, último acesso em 10/11/2010).
} 
participação na região da Toscana (Floridia, 2007), a qual levou a que o modelo francês se tornasse mais conhecido e fosse proposto como referência explícita para a articulação de processos participativos relacionados com as grandes infraestructuras territoriais. Até ao momento, porém, na Toscana não foram experimentadas aplicações concretas do mesmo no âmbito regional, embora o modelo francês se tenha tornado central na articulação da própria Lei 69, aprovada em Dezembro de 2007. Assim, este artigo propõe-se analisar um outro contexto territorial italiano no qual a referência ao "Débat Public" - que entretanto se foi reforçando na literatura e no debate académico nacional - se tornou experiência concreta. Propõe-se, portanto, examinar as especificidades de tal ferramenta, à luz da experiência adquirida no primeiro caso de debate público 'à francesa' em Itália sobre uma grande infraestrutura, que teve lugar em Génova, entre 6 de Fevereiro e 30 de Abril de 2009. O objecto do referido processo foi um novo traçado de auto-estrada com cerca de $20 \mathrm{~km}$ entre Voltri e Génova Oeste, denominado 'Gronda do Poente'.

\section{Na origem do debate: o conflito}

A primeira especificidade do debate público consiste no facto de nascer para enfrentar um conflito já iniciado ou facilmente previsível. As grandes obras tendem a deparar-se com uma dupla oposição: a dos residentes envolvidos (o 'síndroma Nimby'2) e a dos grupos ambientalistas. Os primeiros temem a invasão do 'seu' território, a alteração dos seus ritmos de vida, os perigos para a saúde, a desvalorização das suas casas. Os segundos contestam, de uma forma geral, a utilidade das obras e o modelo de desenvolvimento na qual se inspiram, propondo soluções mais suaves, menos invasivas e correspondentes a um estilo de vida alternativo. $\mathrm{O}$ resultado, assaz frequente, entre a ira dos residentes e os argumentos dos ambientalistas tende a gerar um cocktail explosivo. O protesto que daí surge nem sempre é suficiente para bloquear o projecto, mas é quase sempre capaz de perturbar seriamente o caminho daqueles que o propõem, seja pela força da mobilização que desencadeia, seja pelos argumentos que apresenta.

Como encarar este conflito? Depois das virulentas contestações à linha TGV Lyon-Marselha nos primeiros anos da década de 90 (Lolive, 1999), o governo francês estabelece que os promotores de grandes obras deverão submeter os seus projectos a uma discussão pública preventiva (segundo modalidades específicas que veremos), de modo a poder

\footnotetext{
${ }^{2}$ O acrónimo, bem conhecido, significa "Not in My Backyard" (não no meu quintal).
} 
recolher todas as possíveis objecções e cumprir as suas escolhas de modo mais consciente.

A experiência de Génova também tem origem num conflito que, por sua vez, se arrasta há mais de uma década. O novo traçado da auto-estrada fora projectado há trinta anos para aligeirar a congestão do nó genovês "com os seus atravessamentos mortais". 3 A ideia consistira em redireccionar a actual A10 entre Voltri e Génova Oeste rumo a montante e construir uma nova ponte sobre a Val Polcevera, criando uma alternativa à actualmente intransitável ponte Morandi. Mas a revolta dos habitantes do vale (e em particular de Rivarolo, onde inúmeras casas deveriam ter sido demolidas) levou a que os promotores abandonassem o projecto em 1990 (Ieraci, 2004). Dez anos depois voltava-se a tocar no assunto, e em 2006 era subscrito um protocolo de entendimento entre a entidade gestora das estradas e auto-estradas de Itália (Anas), o governo regional e as entidades locais. Um protocolo que previa um traçado diferente, mas que também implicava fortíssimas interferências com as habitações e com algumas áreas industriais. Tanto o governo municipal como o regional tinham procurado encontrar diferentes soluções e, no final de 2008, chegou-se a definir cinco traçados alternativos (Figura 1). A dada altura,

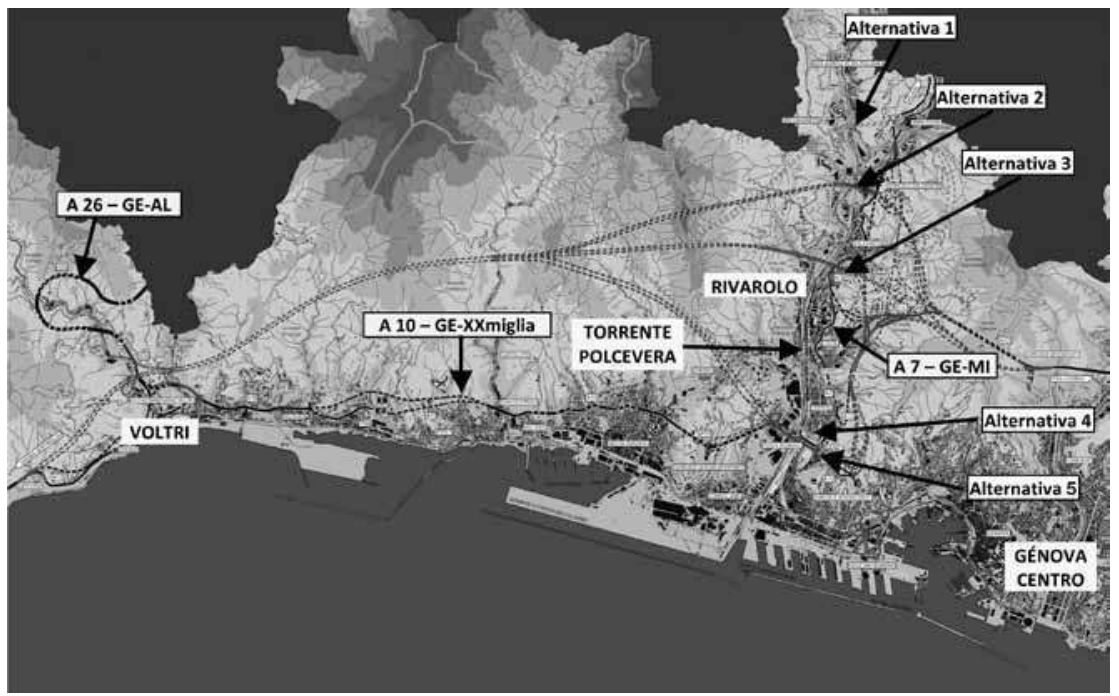

Gronda do Poente. As cinco alternativas de traçado

${ }_{3}$ Da letra da canção de Francesco De Gregori “Viaggi e miraggi” (Canzoni d'amore, 1992). 
o Município de Génova pensou que o melhor seria abrir a discussão ao público - segundo o modelo francês - para evitar chegar a um impasse semelhante ao de 1999, obtendo a plena adesão da entidade promotora, a sociedade Autostrade per L'Italia (ASPI), que estava interessada em experimentar um percurso inovador.

O facto de o debate público nascer da necessidade de lidar com conflitos particularmente acerbos/acesos tem algumas vantagens em relação a outros mecanismos participativos. Efectivamente, a existência do conflito assegura que o que está em jogo seja clarificado perante os cidadãos e que estes sejam induzidos a fazer parte de modo activo no processo (Fung, 2007). Como bem nota Paolo Fareri (2009: 217), "o conflito gera interesse em torno do tratamento dos problemas colectivos [...], leva os actores a definir melhor as suas posições, mobilizando [...] recursos, também de tipo cognitivo, articulando e enriquecendo a definição do problema".

Efectivamente, uma das dificuldades que encontram alguns dispositivos participativos é o facto de se debruçarem sobre objectos 'débeis' ou 'sufocados', pelos quais os cidadãos demonstram pouco interesse e pouca disponibilidade em mobilizar-se. No caso de Génova - como, de resto, no débat public francês - tudo se pode dizer sem que falte paixão e envolvimento: teatros inacreditavelmente apinhados, elaboração de estudos e propostas por parte de associações e cidadãos, tensão e atenção. O objecto da discórdia era evidente e constituía um potente factor de atracção.

\section{Independência, estruturação e transparência}

Todos os processos participativos correm o risco de ser manipulados ou domesticados. Nem sempre existe a preocupação de garantir que quem os gere se encontra numa situação de suficiente autonomia relativamente a quem os promove. Já no caso do débat public essa exigência é levada a sério, dado que em França foi instituída, sob forma de autoridade independente, uma comissão nacional para o debate público, cuja tarefa é decidir quais os casos a encetar, nomeando, para cada um, a commission particulière que assumirá concretamente a sua gestão. Podem, no entanto, levantar-se dúvidas sobre a real independência da comissão nacional. Embora a sua composição seja variada (integra representantes dos ministérios, do sector empresarial e de associações ambientalistas), os seus membros não deixam de ser nomeados pelo governo. Por outro lado, é efectivamente uma instituição separada do governo e dotada de uma missão específica, como por vezes acontece noutros processos participativos.

A solução adoptada pelo Município de Génova, de acordo com a ASPI, foi a de constituir uma comissão formada por especialistas externos ao 
contexto genovês ${ }^{4}$ e dotá-la de uma forte equipa. ${ }^{5}$ A comissão, tal como acontece em França, tinha a tarefa de realizar uma instrução preliminar (que em Génova durou apenas um mês e meio, sendo porém efectuadas nesse período cerca de 60 entrevistas e algumas pesquisas locais), de difundir entre os cidadãos informação sobre o projecto, de estabelecer o calendário do debate e de declarar a sua abertura depois de se ter aprovado a proposta inicial do sujeito proponente, redigida em linguagem não especializada. No caso de Génova a comissão aceitou abrir o debate, ainda que o documento apresentado pela ASPI contivesse algumas omissões graves. Anunciou porém, publicamente, quais os aspectos que seria necessário integrar no documento (facto que depois veio a surgir no desenrolar do debate, ainda que não em todos os aspectos).

Em França, o debate propriamente dito tem uma duração preestabelecida de 4 meses e é estruturado através de encontros públicos realizados nos territórios interessados. Em Génova, os comissários impuseram um período mais curto ( 3 meses). Foram previstos (e realizados com algumas variações) 12 encontros públicos em registo de assembleia: 6 encontros de apresentação, 5 encontros temáticos dedicados aos aspectos mais relevantes do projecto (cenários de mobilidade, problema do amianto e gestão dos estaleiros, impacto na saúde e no ambiente, impacto sobre as habitações e as áreas industriais, projecto integrado) e um encontro conclusivo. Os encontros, tensos e lotados (e muitas vezes turbulentos), realizaram-se predominantemente nos bairros do Poente genovês, directamente envolvidos nos traçados.

Ter à disposição um tempo preestabelecido e, na verdade, relativamente curto, pode parecer uma séria limitação. Na realidade, revelou-se também uma vantagem fundamental. A concentração do processo permitiu acelerar o tempo de reacção e de reflexão por parte de todos os sujeitos interessados e levar à atenção pública preocupações, protestos, apoios, objecções e propostas que de outra maneira dificilmente se fariam ouvir e se poderiam confrontar, ou que seriam infrutíferas por surgirem demasiado tarde, após a conclusão das obras (como acontece quase sempre nos protestos contra as grandes obras). Além disso, a existência de uma data limite para o processo

\footnotetext{
${ }^{4}$ A comissão era composta por Luigi Bobbio (Universidade de Turim), seu presidente, Jean-Michel Fourniau (Inrets, Paris), Andrea Mariotto (Universidade Iuav de Veneza) e Paola Pucci (Politécnico de Milão). A presença do Fourniau foi considerada importante, porque explicita a ligação directa desta experiência ao modelo francês.

5 A equipa pertencente à comissão integrava oito pessoas: Eleanora Parlagreco, Gigi Macciò e Elisa Videtta (Município de Génova), Stefano Bonabello, Laura Longoni e Monica Penco (Departamento de Ciências Políticas e Sociais da Universidade de Génova), Andrea Pillon (Avventura Urbana) e Gianfranco Pomatto (Universidade de Turim).
} 
permitiu diminuir - pelo menos em parte - as preocupações de uma parte da opinião pública genovesa que via o debate público como um pretexto para adiar sine die a decisão.

Em todo o desenrolar do debate a comissão empenhou-se na divulgação de informações e na transparência dos procedimentos. A página electrónica do debate público, ${ }^{6}$ enriquecida dia após dia com novos documentos, cartografias detalhadas, contributos escritos, intervenções no fórum, transmissões e vídeos dos encontros públicos e de um comunicado de imprensa, constituiu um ponto de referência fundamental (em três meses foram registadas 52000 visitas). A escolha mais controversa da comissão foi a de publicar, logo depois da primeira semana de debate, os números das habitações que estariam destinadas a ser demolidas por qualquer um dos cinco traçados. Objectou-se que deste modo se punha mais lenha na fogueira, mas este procedimento de transparência levou a que todos os cidadãos directamente interessados se mobilizassem e que todos os possíveis interlocutores se encontrassem frente a frente, fisicamente (exasperados, mas presentes).

\section{A mobilização dos opositores e o braço de ferro pela representação}

$\mathrm{O}$ débat public à francesa utiliza um método clássico e pouco sofisticado: a convocação de assembleias abertas a todos. E assim se fez também em Génova. O método tem a vantagem de garantir a máxima publicidade e de favorecer uma 'deliberação quente', diferente das abordagens que, baseando-se na construção de arenas restritas ou espaços protegidos (Chambers, 2004), se pautam por um confronto mais racional e comedido - a 'deliberação fria' (Fung, 2007) - com o risco, no entanto, de sacrificar a divulgação do processo. Um efeito colateral desta escolha foi a amplíssima cobertura que a imprensa e as televisões locais reservaram ao debate público. Embora se mostrassem cépticos ou até desconfiados relativamente à validade da iniciativa, os meios de comunicação social locais referiram os encontros, deram voz aos protagonistas institucionais e a simples cidadãos, desenvolveram investigações sobre o território e dedicaram ao assunto muito espaço de debate. Ao contrário de outras experiências participativas, o debate público de Génova não teve nada de clandestino.

A existência de espaços abertos em que cada um poderia fazer-se ouvir constituiu um estímulo potentíssimo para a mobilização dos opositores. No Poente genovês existiam alguns comités históricos que assumiram subitamente a dianteira do protesto, mas no espaço de poucas semanas abandonaram-no ou reorganizaram-se em comités de cidadãos em todas

\footnotetext{
${ }_{6}^{6} \mathrm{http}: / /$ urbancenter.comune.genova.it/spip.php? rubrique7068.
} 
as povoações da Val Polcevera. Ao longo do debate, estes deram vida à "Coordenação dos Comités da Val Polcevera e do Poente", organizando assembleias e manifestações.

Deste cenário surge também um problema. Todos os processos participativos procuram que o simples cidadão se expresse, mais do que os grupos organizados. A dada altura, a comissão estabeleceu que, nas 6 assembleias de apresentação, as intervenções do público fossem sorteadas de modo a dar a mesma oportunidade a todos os participantes. Os comités contestaram este procedimento, pois poderia ter posto em risco o seu monopólio na representação. De tal forma que, no primeiro encontro público sobre o território (Voltri, 14 de Fevereiro de 2009), pediram permissão para abrir a discussão com uma intervenção e, face à recusa da comissão, convidaram os presentes a abandonar a sala. $\mathrm{O}$ braço de ferro pela representação arrastou-se durante a totalidade dos três meses do debate com diferentes desfechos. Chegou-se, muitas vezes, a um ponto de quase ruptura, mas sem nunca o ultrapassar. A comissão tinha todo o interesse em fazer algumas concessões para encerrar o debate e os comités não podiam permitir pôr termo a um mecanismo que oferecia visibilidade às suas posições na arena citadina. Todavia, no decorrer do debate, a sua influência sobre os cidadãos participantes não obteve sempre saldo positivo. Se a grande maioria dos participantes nos encontros públicos estava claramente em sintonia com a posição dos comités, nem todos os presentes se mostraram dispostos a confiar plenamente neles. Quando os comités pediram ao público para abandonar a sala nos encontros de Voltri (14 de Fevereiro) e Sampierdarena (18 de Abril), uma parte considerável da plateia declinou o convite.

\section{O desequilíbrio na participação}

O próprio método de assembleia, dado que se baseia na auto-selecção dos participantes (Bobbio, 2006), tende a gerar um desequilíbrio na composição dos mesmos. Este facto verificou-se em Génova: a participação foi intensa e apaixonada, mas também unilateral. Nas assembleias, as posições contrárias à auto-estrada foram absolutamente dominantes e os poucos cidadãos com a intenção de apoiar o projecto - ainda que brandamente - viriam a ser bruscamente silenciados.

Tal desequilíbrio é, efectivamente, um fenómeno constante também no débat public francês. A razão é facilmente compreensível. Encontramo-nos perante obras que tendem a gerar benefícios difusos (neste caso para os automobilistas, para o tráfego de mercadorias, para a cidade como um todo, etc.), mas ao mesmo tempo geram custos concentrados sobre comunidades específicas e é natural que os potenciais "prejudicados” tenham 
preferências mais intensas que os potenciais "beneficiários", tendo assim razões mais urgentes para participar.

Um desequilíbrio deste género não é necessariamente negativo. A parte fundamental de um debate público é a de tornar evidentes os conflitos latentes. No caso de Génova, o debate permitiu destapar uma panela de água a ferver que, mais tarde ou mais cedo, explodiria. Um debate público é, de qualquer modo, uma experiência social in vivo. Faz emergir problemas que de outro modo permaneceriam escondidos e também abre caminho para a identificação de soluções mais aceitáveis.

Um certo desequilíbrio entre as posições pró e contra pode ser justificado também no plano ético. Na controvérsia em torno da Gronda alegaram-se, mesmo que implicitamente, duas concepções éticas diferentes. A primeira, de matriz utilitária, considera como justas as soluções que beneficiam o maior número de indivíduos; no entanto, no caso de Génova, admite o sacrifício de pequenas comunidades em nome de interesses colectivos mais gerais. A segunda concepção, que se inspira na teoria da justiça de John Rawls, considera como justas as soluções que acarretam menores custos para os grupos em desvantagem; no entanto, no caso de Génova, favorece as escolhas que minimizam os riscos para a comunidade directamente afectada pela infraestrutura. Ao aceitar esta segunda concepção, torna-se evidente que aos grupos desfavorecidos deverá ser assegurada a máxima presença no debate, de modo a compensar a sua posição minoritária no seio de uma comunidade mais vasta.

Dito isto, as posições favoráveis à Gronda não foram, efectivamente, asseguradas. O dispositivo do debate público 'à francesa' não consiste apenas na assembleia, mas prevê também outras formas de expressão. Em Génova foram activados laboratórios mais restritos e, sobretudo, foi-se beber à experiência francesa a ideia dos 'Cadernos dos Actores', ou seja, uma publicação - a cargo da comissão - de reflexões, análises ou propostas desenvolvidas por grupos ou por iniciativa individual de alguns cidadãos. No decurso do debate foram publicados 45 cadernos que ofereceram uma vasta gama de orientações e, frequentemente, interessantes soluções alternativas. ${ }^{7}$

Os actores favoráveis à nova auto-estrada reagiram, compreensivelmente, com menor tempestividade, mas conseguiram mesmo assim exprimir as suas razões e, em alguns casos, encontrar momentos de confronto com os seus antagonistas. As organizações sindicais, as associações de empreendedores, a Câmara do Comércio, a Autoridade Portuária, argumentaram nos 'Cadernos dos Actores', com diferentes tónicas no discurso, as suas posições a favor da Gronda. A imprensa local deu amplo destaque às suas posições.

\footnotetext{
${ }^{7}$ http://urbancenter.comune.genova.it/spip.php?article1292.
} 
Ao longo do debate, a Câmara do Comércio lançou uma campanha publicitária a favor da obra e promoveu o "Grupo Gronda de Génova" na tentativa de sustentar "a realização da Gronda do Poente sem qualquer lógica partidária ou política, independentemente do traçado que será escolhido". ${ }^{8}$

\section{O "como" e o "se"}

A questão fundamental a que um debate público sobre uma grande infraestrutura procura responder diz respeito ao objecto específico do confronto. Pode discutir-se apenas o 'como' (o traçado, as características da obra) ou também o 'para quê' (a sua utilidade)? Em Génova, os poderes que o Município atribuiu à comissão eram claros: consideravam exclusivamente a discussão sobre cinco alternativas de atravessamento da Val Polcevera. Isto comportava a exclusão do debate de todas as outras partes do traçado para as quais não estavam previstas alternativas (em particular, o nó de Voltri) e impedia, sobretudo, a abertura do debate à oportunidade da Gronda, dado que a obra estava já definida a nível nacional e que o Município de Génova se tinha empenhado explicitamente sobre a mesma no programa político de 2006 e não podia consentir que o debate público a pusesse em risco.

Todavia, a partir do momento em que o debate se abriu, estas limitações atropelaram-se. A contestação incidiu também nas partes do traçado que inicialmente não foram incluídas entre os temas do debate. E, sobretudo, a questão da oportunidade da obra transformou-se rapidamente num dos focos centrais do debate. As assembleias foram dominadas pelas críticas à nova auto-estrada, considerada custosa e inútil, e pela formulação de possíveis alternativas a partir do transporte ferroviário, a rede rodoviária regular ou a adopção de formas alternativas de mobilidade 'suave'. Descobriu-se que a nova auto-estrada não era universalmente considerada como um remédio para a congestão do nó genovês, ao contrário do que supunha inicialmente o Município.

A comissão não teve outra hipótese senão aceitar esta abertura. Convocou um encontro público sobre a análise dos fluxos de mobilidade, para verificar - na presença de numerosos especialistas - a fiabilidade das previsões fornecidas pela ASPI sobre o aumento do tráfego rodoviário e em que medida seria exequível a alternativa ferroviária. E, no seguimento deste encontro, desenvolveu um laboratório sobre os cenários de mobilidade em que os grupos antagonistas (ambientalistas, comités de cidadãos, ASPI, entidades ferroviárias, Município, Província, Confindustria, Autoridade Portuária) se confrontaram sobre planos, dados e projecções.

\footnotetext{
${ }^{8}$ Câmara do Comércio de Génova, Gronda di Genova. Posizione del gruppo "Gronda di Genova" in mérito alla realizzazione dell'opera Gronda di Ponente, Caderno dos Actores de 30 de Abril de 2009.
} 
Em essência, o debate foi absorvido pelos movimentos do confronto sobre as cinco alternativas de traçado, mas abordou depois reflexões mais amplas sobre a mobilidade e a exploração de possíveis soluções alternativas à auto-estrada. A redefinição dos temas em discussão mostra que o debate público não se tratou de um ritual pré-determinado. É interessante notar como a dada altura se desenvolveu uma controvérsia acesa nos primeiros anos de experimentação do debate público em França até que a lei de 2002, que reformou o processo, acabou com as dúvidas afirmando que o debate público "se refere à oportunidade, aos objectivos e às características do projecto” (art. 121-1, Code de l'environnement).

\section{Contraposição e deliberação}

O debate público de Génova não foi, prevalentemente, um evento diatónico ou deliberativo. Nas assembleias dominaram os testemunhos de indignação e ressentimento: os cidadãos que tomaram a palavra mostraram sentir-se vítimas de uma injustiça inaceitável devido a uma obra que transformaria, incompreensivelmente, as suas vidas, poria em perigo a sua saúde e demoliria as suas casas. Os comités, por sua vez, afirmaram continuamente a sua oposição à nova auto-estrada em nome de soluções alternativas. E se o pano de fundo foi o dos testemunhos, por um lado, e o da contraposição, por outro, não se pode dizer que os argumentos não tenham marcado e que não se tenha instalado - sobretudo nos interstícios do debate - qualquer forma de confronto efectivo.

Contribuíram para este cenário os outros 30 especialistas envolvidos que, intervindo nas assembleias, em grupos mais restritos ou com documentos escritos, permitiram evidenciar, também com posições claramente diferentes, questões delicadas como aquelas que dizem respeito às previsões do tráfego, à relação custo/benefício da obra, ao tratamento do amianto ou à gestão dos estaleiros.

Um contributo muito importante surgiu dos cidadãos que, por iniciativa individual, formularam nos 'Cadernos dos Actores' propostas alternativas de traçado, que foram depois discutidas em encontros restritos com os técnicos da sociedade Autostrade per l'Italia (ASPI). Em particular, três cidadãos, independentes uns dos outros, levantaram algumas questões muito relevantes sobre uma parte do traçado que até então não era considerada problemática (o troço sobre a margem esquerda de Polcevera, a montante da A7), formulando propostas alternativas que permitiriam evitar o impacto em algumas áreas residenciais. Os técnicos da ASPI levaram a sério as suas indicações, trabalhando com os cidadãos e, depois de vários encontros, reuniram-se para reformular esta parte do traçado. 
O encontro foi áspero, mas o debate permitiu, pelo menos em parte, reconduzi-lo a um confronto argumentado. Verificou-se um processo pouco invulgar de divulgação da informação e de aprendizagem colectiva. Este processo de aprendizagem contaminou também o sujeito proponente (Autostrade per l'Italia), que se viu a dialogar com os cidadãos numa situação tensa e difícil, conseguindo porém dar respostas pertinentes e reconsiderar algumas das suas próprias escolhas. Por altura do encerramento do debate, enquanto os cidadãos se tornam conhecedores dos aspectos técnicos, o sujeito proponente torna-se mais consciente das características e problemas do território.

\section{O êxito}

O débat public 'à francesa' não toma decisões e não tem qualquer eficácia jurídica. A comissão limita-se a tornar público um relatório final no qual apresenta as posições, os argumentos e as propostas surgidas durante o confronto. Posteriormente, a palavra passa para o sujeito proponente que, dentro de um prazo preestabelecido, declara se pretende avançar com o projecto e, em caso afirmativo, como pretende considerar os argumentos resultantes do debate e apresentados no relatório final da comissão.

Em Génova, a comissão apresentou o seu relatório final ${ }^{9} \mathrm{em}$ meados de Maio de 2009, quinze dias depois do encerramento do debate. Por sua vez, a ASPI tornou públicas as suas intenções nos quinze dias seguintes, ${ }^{10}$ num documento em que enumera as 'descobertas' surgidas dos encontros públicos. Por exemplo:

Pensávamos que as optimizações projectuais efectuadas no passado relativamente aos projectos na zona de Voltri fossem objectivamente suficientes; em vez disso a cidadania veio demonstrar os seus limites evidenciando os seus pontos fracos ... na área de Crevari e Vesima... (itálico no original) (La dichiarazone di Autostrade per l'Italia, slide 1.0.2)

A ASPI reconhece que "o debate não foi nem virtual nem fingido [...] e portanto serviu [...] para que o projecto adquirisse valores acrescidos [...] que assim fizeram com que se conseguisse reconfigurar e propor uma nova solução projectual" (ibidem, slide 1.0.6.). De facto, a solução definida

\footnotetext{
${ }^{9}$ Comissão para o debate público sobre a Gronda de Génova, Relazione conclusiva. Posizioni, argomenti e proposte emersi dal dibattito, http://urbancenter.comune.genova.it/IMG/pdf/gronda_ genova_relazione_conclusiva_def.pdf.

${ }^{10}$ La dichiarazione di Autostrade per l'Italia, http://www.urbancenter.comune.genova.it/sites/ default/files/La\%20dichiarazione\%20di\%20autostrade\%20per\%20l'Italia\%20-\%20parte\%20 terza.pdf.
} 
pela ASPI é notavelmente diferente da original, tendo em consideração muitos dos argumentos levantados ao longo do debate. É escolhida como base uma das cinco alternativas de atravessamento de Val Polcevera (a alternativa $\mathrm{n}^{\circ} 2$ ), aquela que causa menor impacto sobre as habitações e sobre as áreas industriais, e são introduzidas correcções notáveis, seja na parte Oeste (Voltri), seja na parte Este (Sinistra Polcevera) do traçado. A solução acolhe ainda a proposta mais vezes referida no debate, a de impedir o tráfego pesado na velha auto-estrada A10, direccionando-o integralmente para a nova artéria.

Esta solução foi aprovada pelo governo da Região e da Província e pelo Município de Génova. À data do presente texto (Setembro de 2009), está a trabalhar-se para torná-la oficial através da sua inclusão no novo programa político. Este documento deverá estabelecer também a criação de um observatório local sobre o controlo do projecto e o plano de intervenções compensatórias especificado durante o debate e, em particular, a criação de um laboratório expressamente dedicado aos problemas do 'depois'.

Deve acrescentar-se que o debate público custou 191000 euros (cerca de um quinto da média dos débats publiques franceses), sendo que $37 \%$ deste montante esteve a cargo do Município de Génova e 63\% a cargo da ASPI. Esta última forneceu o equipamento das salas, suportou as despesas de imprensa e de divulgação do material informativo disponibilizado pela comissão, assim como a remuneração de parte da equipa escolhida pela comissão.

\section{Sobre a ambivalência do debate público}

Segundo Simon Charbonneau (2010), o debate público revela frequentemente um carácter ambivalente. Este juízo poderia ser formulado para qualquer mecanismo participativo. De facto, esses dispositivos são constituídos por um conjunto de regras de procedimento que podem conduzir a participação em direcções diferentes ou até opostas - para domesticar o conflito ou para levá-lo a bom porto, para dar a palavra ou para calar. Não faz sentido deduzir das normas legislativas que o debate público "à francesa' é em si mesmo um mecanismo "anestesiante da dissidência", como escreveu peremptória mas imprudentemente Alessandra Algostino (2008). Se queremos falar de "ambivalência", devemos levar a sério o significado do prefixo "ambi" e perceber que o dispositivo do debate público poderá pender para um lado ou para o outro, ou até propiciar uma convivência de perspectivas de leitura por parte de diferentes actores. Eventualmente, a análise crítica deverá procurar clarificar quais as condições favoráveis a um ou a outro cenário. 
O caso de Génova mostra que as potencialidades democráticas do debate público são pelo menos idênticas aos seus limites. Em Génova, a abertura do debate obrigou o sujeito proponente a pôr as cartas na mesa (como nunca acontece em Itália) e a argumentar em público as próprias escolhas viárias e projectuais. Permitiu divulgar informação detalhada entre a população. Solicitou a mobilização da comunidade local e fomentou a sua organização. Obrigou todas as partes em causa a encontrar bons argumentos (também técnicos) para sustentar as suas posições. Criou ocasiões de confronto entre portadores de visões opostas. Criou condições para o envolvimento do território nas sucessivas fases de projecto. Efeitos semelhantes são comuns à maioria das experiências francesas.

Um problema delicado é o da independência da comissão relativamente aos sujeitos proponentes. É claro que nenhuma regra de procedimento pode assegurar essa independência de modo absoluto, ainda que se possam criar condições para torná-la possível. No caso de Génova, correndo o risco de 'me elogiar' e assim 'me sujar', penso poder dizer que a comissão foi capaz de dar voz a todos e demonstrar possuir a autonomia necessária tanto relativamente à ASPI como ao Município de Génova, como reconheceram muitas vezes os próprios participantes no debate.

A ambivalência está, sobretudo, no êxito destes processos. Ainda que o debate incida (pelo menos em França) sobre o 'como' e o 'para quê', no final os projectos são quase sempre confirmados (mesmo que com alterações mais ou menos relevantes). Sobre 31 debates públicos concluídos em 2006, apenas em 5 casos o proponente declarou querer abandonar o projecto na sequência do debate, enquanto nos outros 26 casos a utilidade da obra não foi posta em causa. O problema não diz respeito ao carácter puramente consultivo do processo participativo, que deixaria o caminho desimpedido para o proponente. Para além do facto de ser impossível imaginar como uma sede informal e aberta possa tomar decisões vinculativas para a colectividade passando por cima das instituições representativas (quem deveria decidir: uma assembleia? formada por quem?), a falta de poder decisivo constitui um importantíssimo recurso. Permite um confronto mais livre, aberto e vital; liberta a discussão do embaraço das formalidades. Naturalmente, é verdade que no final o proponente poderá escolher em plena autonomia quais as propostas a acolher e como o fazer, mas - depois de um confronto rico, tenso e articulado - não terá particular interesse em descurar as razões aduzidas pela população de um território no qual deverá trabalhar nos anos subsequentes. Deverá examinar-se, caso a caso, o grau de influência que o debate conseguiu obter sobre as decisões finais. 
O problema principal diz respeito à natureza do interlocutor. No modelo francês, ele é constituído por uma sociedade (pública ou privada) que abre o debate apresentando uma proposta e o fecha declarando as suas intenções. Mas o sujeito proponente pode não estar estruturalmente em posição de dar resposta a todas as questões levantadas ao longo do debate. Por exemplo, no caso de Génova, muitos cidadãos sustentavam que o problema da congestão deveria ser resolvido com o potenciamento do transporte ferroviário metropolitano, mais do que com a construção de uma nova auto-estrada. Face a estas concepções, a ASPI não podia responder senão do seguinte modo: "O que podemos dizer-vos? Nós fazemos auto-estradas". É evidente que o problema da mobilidade de um nó metropolitano não pode ser desfeito por uma concessionária de auto-estradas. Certamente que durante o debate se pronunciaram também outros sujeitos com visões e responsabilidades mais amplas; no entanto, no final do processo, a última palavra cabe à sociedade Autostrade per l'Italia. Trata-se, portanto, de um dilema difícil de resolver.

A solução adoptada pela ASPI no fim do debate pode ser validada de maneiras diferentes consoante os pontos de vista. Pode ser considerada como uma escolha inovadora, que não seria possível sem os contributos resultantes do debate (e isto é seguramente verdade). E pode ser considerada como um remendo que esconde uma total mudança de opinião sobre o modo de planear a mobilidade na área metropolitana genovesa (e há qualquer coisa de verdade também nisto). Esta ambivalência parece-me impossível de suprimir em confrontos públicos deste tipo.

Todavia, apesar dos seus limites e das suas ambivalências, o debate público sobre as grandes infraestruturas representa uma ruptura radical relativamente ao clima de petulância e arrogante autoritarismo que, em Itália, marca o projecto de grandes obras. A divulgação de processos deste género, se conduzidos com atenção e com respeito pelas razões dos cidadãos, não poderá fazer senão bem à democracia, ao ambiente, às comunidades locais e também às infraestruturas do país. 


\section{Referências bibliográficas}

Algostino, Alessandra (2008), "L'Osservatorio per il collegamento ferroviario Torino-Lione come case study sulla democrazia e sul dissenso", Democrazia e diritto, 2, 231-246.

Bobbio, Luigi (2006), "Dilemmi della democrazia partecipativa", Democrazia e diritto, 44, 11-26.

Chambers, Sarah (2004), "Behind Closed Doors: Publicity, Secrecy, and the Quality of Deliberation”, Journal of Political Philosophy, 12(4), 389-410.

Charbonneau, Simon (2010), "Les expériences françaises des différentes échelle: de l'ambivalence de la participation", in Umberto Allegretti (org.), Democrazia Partecipativa. Esperienze e prospettive in Italia e in Europa. Firenze: FUP, 277-284.

Fareri, Paolo (2009), Rallentare. Il disegno delle politiche urbane. Milano: F. Angeli.

Floridia, Antonio (2007), "Democrazia deliberativa e processi decisionali: la legge della Regione Toscana sulla partecipazione”, Stato e mercato, 82, 83-110.

Fung, Archon (2007), "Minipublics: Deliberative Designs and Their Consequences", in Shawn W. Rosenberg (org.), Can the People Govern? Deliberation, Participation, and Democracy. New York: Palgrave, 159-183.

Ieraci, Giuseppe (2004), "Genova: bretella Voltri-Rivarolo", Archivio IsaP, 7, Le decisioni di opera pubblica e di urbanistica nelle città. Milano: Giuffrè, 581-616.

Lolive, Jacques (1999), Les contestations du TGV méditerranée: projet, controverse et espace public. Paris: L'Harmattan.

Mansillon, Yves (2006), "L'esperienza del 'débat public' in Francia”, Democrazia e diritto, 3, 101-114.

Revel, Martine; Blatrix, Cécile; Blondiaux, Loïc; Fourniau, Jean-Michael; Dubreuil, Bertrand Hériard; Lefebvre, Rémi (orgs.) (2007), Le débat public: une expérience française de démocratie participative. Paris: La Découverte. 